\title{
MAPEAMENTOS SOCIAIS COMO FERRAMENTA PARA DISCUSSÃO DE POLÍTICAS PÚBLICAS PARA O RECONHECIMENTO FORMAL DE BENZEDEIRAS NO PARANÁ
}

\author{
Antonio Michel Kuller Meira \\ Universidade Estadual do Centro-Oeste (UNICENTRO), \\ Guarapuava, Paraná, Brasil
}

\begin{abstract}
Resumo: Este trabalho apresenta análises sobre o processo de mapeamentos sociais de benzedeiras, benzedores, curadores, costureiras de machucadura, remedieiros, massagistas tradicionais e parteiras realizados nos municípios de Rebouças e São João do Triunfo, no Paraná. Este trabalho, realizado pelo Movimento Aprendizes da Sabedoria, com o apoio de pesquisadores do Projeto Nova Cartografia Social, representou uma ferramenta importante para identificar a diversidade de sujeitos que se autoidentificam como pessoas que exercem ofícios tradicionais de cura religiosa e saúde popular. Percebe-se que os mapeamentos sociais foram um instrumento para gerar discussão sobre práticas tradicionais e conflitos enfrentados pelos grupos, bem como para dar visibilidade aos poderes públicos para a elaboração de políticas públicas de reconhecimento.
\end{abstract}

Palavras-chave: Mapeamento social. Ofícios tradicionais. Conflitos. Política pública. 
INTRODUÇÃO

No Paraná, encontramos diversas pessoas que formam grupos sociais tradicionais que se autoidentificam como benzedeiras, benzedores, curadores, curadeiras, costureiras (os) de rendidura, massagistas tradicionais, remedieiros e parteiras. Esses grupos estão localizados tanto em meio rural como urbano e apresentam uma especificidade própria no modo de viver, de se relacionar com a natureza, principalmente no que se refere a conhecimentos tradicionais associados a plantas medicinais e diversos fatores culturais diferenciados que formam uma identidade própria. De acordo com levantamentos do Movimento Aprendizes de Sabedoria (MASA, 2015), estima-se um número aproximado de 17.000 detentores de ofícios tradicionais de cura religiosa e saúde popular no Paraná.

Destacamos neste trabalho o papel histórico dos conhecimentos e práticas tradicionais de cura utilizados em diversos lugares no Brasil, tradicionalmente orientados por benzedores, curandeiros, costureiras de rendiduras, pajés, remedieiros, raizeiros, massagistas tradicionais, homeopatas tradicionais, parteiras, entre outros. No Brasil, esses conhecimentos tradicionais representam um patrimônio imaterial imensurável, presente especialmente entre os benzedores, raizeiras, povos das florestas e das águas, povos indígenas, adeptos de religiões de matrizes africanas, entre outros.

A saúde, principalmente nas comunidades rurais até a década de 1970 no Paraná, era basicamente tratada com medicamentos extraídos das florestas e dos quintais, além de contar com os conhecimentos sobre plantas medicinais e práticas tradicionais de cura de curandeiros, benzedeiras, costureiras de rendidura, massagistas tradicionais, remedieiros e parteiras. Essas pessoas, no exercício desses ofícios tradicionais, detêm uma diversidade de conhecimentos sobre plantas medicinais, simpatias, defumação, oração, benzimentos, remédios caseiros, garrafadas, etc.

Com o passar do tempo, essas práticas foram sendo prejudicadas com o surgimento dos medicamentos alopáticos e da medicina oficial, bem como em virtude da repressão que esses ofícios passaram a sofrer a partir de 1830. Isso ocasionou indiretamente a diminuição dos conhecimentos sobre o uso e o manejo das plantas medicinais, mas, mesmo assim, a prática de remédios caseiros, benzimentos, defumação, costuras permaneceram presentes. $\mathrm{O}$ acesso aos medicamentos alopáticos pelos moradores dessas comunidades muitas vezes se tornou inviável, pois as políticas públicas de saúde não asseguram o direito a todos os medicamentos, impedindo a aquisição desses remédios que, em sua maioria, têm um alto custo. Sendo 
assim, as práticas de cura tradicionais, em muitos casos, tornam-se a única opção de tratamento da saúde de pessoas e animais, permitindo, dessa forma, a resistência do uso tradicional das práticas e saberes tradicionais de cura.

As práticas de saúde popular sofreram, ao longo da história, um lento processo de marginalização. Até hoje, pessoas ligadas a entidades religiosas discriminam quem exerce esses ofícios e detêm esses conhecimentos. Outro fator que também colabora para a perda dessas práticas é a marginalização, por pessoas ligadas a entidades de saúde, do uso dos fitoterápicos, o que afeta diretamente a reprodução social desses conhecimentos e dessas práticas tradicionais.

As práticas tradicionais de cura popular contavam com uma regulamentação pela Fisicatura até o ano de 1830. Esse órgão era responsável por dar a carta aos praticantes da arte de curar e oficializá-los.

Os próprios números encontrados no levantamento da documentação da Fisicatura indicam que a maior parte dos sangradores, curandeiros e parteiras não se oficializava. Contudo os que quisessem fazê-lo ou se sentissem pressionados pela fiscalização sabiam que havia uma instituição que legitimava suas artes. Depois de 1828, não mais (PIMENTA, 2003, p. 315).

Com o fim da Fisicatura, não havia órgão competente para organizar tais demandas. Curandeiros, sangradores e parteiras da época ficavam muitas vezes na"ilegalidade" perante as leis, mas, mesmo assim, resistiam, praticando suas artes de curar. Diante dessa situação, destaca Pimenta (2003, p. 316): "Portanto, depois de 1828, essa categoria nem sequer era considerada. Os conhecimentos sobre as plantas nativas já não garantiam a legitimidade de suas práticas". Começa nessa época uma forte repressão aos ofícios tradicionais, somente o saber científico avaliado e documentado tinha o direito de dominar tais práticas de cura.

De acordo com Pimenta (2003, p. 319), "A novidade estava na progressiva organização de uma corporação médica e na luta dessa categoria pelo monopólio das práticas de cura". Os ofícios tradicionais de cura passaram, desse momento em diante, por um processo de marginalização e deslegitimação, afetando a reprodução social desses conhecimentos e ofícios. Assim, a prática de ensinar o preparo de remédios e das demais artes de curar fica na marginalidade, sem amparo jurídico.

Os praticantes dessas artes de curar são, em vários lugares, o primeiro socorro da população local e, muitas vezes, o único recurso que dispõe as pessoas de menor renda. Como destaca uma liderança do MASA. "Quem nos 
procura geralmente são os mais pobres, os que não têm recurso, o rico só procura depois que vai ao médico e não adianta"(Agda de Andrade Cavalheiro).

A fala da benzedeira é confirmada por Pimenta (2003, p.321): "Assim, os curandeiros continuavam a ser considerados o recurso de que dispunham os pobres. Eram pessoas de camadas subalternas que tratavam de miseráveis, os quais não teriam mesmo condições de pagar a visita de médicos diplomados".

Esse quadro apresentado leva à reflexão sobre as iniciativas que poderiam colaborar na valorização dos ofícios tradicionais na região sudeste do Paraná. Entidades populares como o Instituto Equipe de Educadores Populares promovem debates no seu coletivo sobre o tema apresentado e começam a elaborar algumas estratégias de ação.

A discussão que segue neste trabalho é fruto do acompanhamento e da assessoria realizados junto ao movimento das benzedeiras, de 2006 a 2010, e também do esforço atual de aprofundamento da análise e da reflexão, em uma pesquisa de mestrado, sobre a educação não formal realizada por movimentos sociais e suas implicações para o fortalecimento da identidade desses ofícios tradicionais.

\section{A ORGANIZAÇÃo DAS BENZEDEIRAS DO PARANÁ EM MOVIMENTO SOCIAL}

A partir da análise dos conflitos encontrados na região sudeste do Paraná, é que os benzedores e demais ofícios tradicionais organizam-se em um movimento social denominado Movimento Aprendizes da Sabedoria (MASA). Esse movimento social surge de um processo fomentado na região entre os anos de 2002 e 2008, no qual as aprendizes da sabedoria, organizadas em grupos, juntamente com a Pastoral da Criança, e apoiadas pelo Instituto Equipe de Educadores Populares, discutiam os saberes relacionados às plantas medicinais e realizavam oficinas de preparo de remédios caseiros em algumas comunidades de Irati e região.

Esse trabalho tinha como objetivo principal a organização das comunidades para a valorização e o resgate do conhecimento popular sobre as plantas medicinais, bem como os chamados ofícios tradicionais de saúde popular como: benzedeiras, benzedores, curandeiros, costureiras(os) de rendidura, massagistas tradicionais, remedieiros e parteiras.

A marginalização de práticas populares de cuidado com a saúde e a consequente perda de conhecimentos, somada à repressão aos ofícios tradicionais de saúde popular, motivou a promoção de reuniões a fim de expandir e valorizar o uso e o preparo de plantas medicinais, bem como a identificação desses ofícios. Nesses encontros e oficinas, percebeu- 
se o vasto conhecimento dos detentores desses ofícios sobre plantas medicinais, preparo de remédios caseiros como chás, xaropes, pomadas, tinturas, garrafadas, etc. Também somam-se a esses conhecimentos práticas tradicionais de cura como benzimentos, simpatias, orações, defumações, rezas tradicionais, realizados principalmente por pessoas mais idosas e muitas vezes correndo o risco de desaparecimento.

O processo de organização dos ofícios tradicionais de saúde popular partiu de uma iniciativa da Associação Aprendizes da Sabedoria de Medicinais e Agroecologia (ASA), que organizou o primeiro fascículo da série"Faxinalenses no sul do Brasil", com o titulo: "Faxinalenses, fé, conhecimentos tradicionais e práticas de cura". Esse trabalho ocorreu no ano de 2007 e foi apoiado por pesquisadores e instituições parceiras do Projeto Nova Cartografia Social do Brasil e também pelo Instituto Equipe de Educadores Populares (IEEP).

O processo de realização do fascículo da cartografia social propiciou a realização de diversas oficinas de troca de conhecimentos tradicionais e ampliou o debate sobre os problemas enfrentados pelas benzedeiras e pelos praticantes dos demais ofícios tradicionais. Várias foram as ameaças sofridas pelos grupos, principalmente a repressão por parte de pessoas ligadas a instituições religiosas e à medicina oficial, além dos preconceitos e da desvalorização de que os praticantes desses ofícios são vítimas. Esses conflitos relatados pelas benzedeiras provocam um desinteresse gradual pelos conhecimentos das plantas medicinais e práticas de curas utilizadas. Outro problema narrado é a privação dos recursos naturais, especialmente das plantas medicinais nativas utilizadas para os tratamentos e o preparo dos remédios caseiros, cujo acesso tornava-se muitas vezes impossibilitado.

O primeiro fascículo da série "Faxinalenses no sul do Brasil", linha de pesquisa do Projeto Nova Cartografia Social dos Povos e Comunidades Tradicionais, contou com a participação de três comunidades faxinalenses: Faxinal dos Seixas, no município de São João do Triunfo; Faxinal Marmeleiro de Cima, em Rebouças, e Faxinal Rio do Couro, em Irati, no Paraná. Através da autocartografia, foi mostrada a localização dos ofícios tradicionais e das práticas tradicionais, com o uso de plantas medicinais nativas e cultivadas nos quintais, além de várias práticas tradicionais de cura, como benzimentos, simpatias, orações, rezas, defumações, entre outras.

Esse fascículo foi o motivador para a discussão dos ofícios tradicionais nas comunidades faxinalenses, visto que, nos mapas das comunidades, apareceram diversos ofícios tradicionais de cura como benzedores, benzedeiras, curandeiros, costureiras de rendidura e parteiras. A partir desse trabalho, o Instituto Equipe de Educadores Populares e outras entidades da região 
observaram que muitos dos conhecimentos sobre práticas tradicionais de cura e plantas medicinais estavam presentes nesses ofícios, os quais necessitavam de um processo de valorização para que esses conhecimentos e práticas tradicionais de cura permanecessem vivos entre as novas gerações. Nesse sentido, começa a discussão para a organização de uma entidade para dar visibilidade e reconhecimento a esses conhecimentos e práticas tradicionais ligados à saúde popular, presentes nos ofícios tradicionais das benzedeiras e demais ofícios, bem como a valorização da cultura religiosa tradicional local.

De acordo com o MASA (2012), foi em 4 de abril de 2008, na comunidade tradicional de Faxinal Marmeleiro de Baixo, no município de Rebouças, Paraná, que ocorreu o primeiro encontro comunitário dos detentores de ofícios tradicionais de cura religiosa e saúde popular. Já em 6 de setembro de 2008, realizou-se o $1^{\circ}$ Encontro Regional das Benzedeiras, Benzedores, Rezadeiras, Curadores, Costureiras de Machucaduras e Parteiras, em Irati, nas dependências da Universidade Estadual do Centro-Oeste (UNICENTRO), com o tema "Cuidar da vida é a nossa missão". Nesse encontro, foram realizados debates, trocas de experiências e oficinas temáticas, além da discussão sobre as dificuldades encontradas pelos praticantes desses ofícios. Participaram detentores de ofícios tradicionais de vários municípios, como São João do Triunfo, Palmeira, Rebouças, Irati, Boa Ventura de São Roque, Turvo, Prudentópolis, Inácio Martins, Guarapuava, dentre outros. Nesse encontro, surgiu a proposta de organizarem-se em movimento social, passando daquele momento em diante a denominar-se Movimento Aprendizes da Sabedoria (MASA). Também nesse encontro foram articuladas algumas propostas, como a luta por políticas públicas de promoção e reconhecimento dos ofícios tradicionais de saúde popular, como benzedeiras, benzedores, curandeiros, costureiras, costureiros de rendiduras, remedieiros e parteiras. Ainda com base nas demandas do encontro, definiu-se a defesa do livre acesso às plantas medicinais nativas. Dentre outras ações apontadas pelas benzedeiras, destacam-se a luta para a promoção da cultura religiosa local e a programação de ações de repasse dos conhecimentos e práticas tradicionais de cura a novas gerações.

Outra proposta do encontro foi realizar a identificação das benzedeiras nos municípios através do mapeamento social dos ofícios tradicionais, realizado em 2009 e 2011, nas respectivas cidades de Rebouças e São João do Triunfo, no Paraná.

Atualmente, o movimento social das benzedeiras conta com uma coordenação composta por representantes dos municípios de Irati, Rebouças e São João do Triunfo. Desde sua organização, a linha central do MASA é o 
resgate e a valorização das práticas e dos conhecimentos tradicionais de saúde popular e da religiosidade popular local.

Diversos eventos de formação têm sido organizados, como encontros, reuniões, oficinas, cursos, além da produção de material de apoio, como cartilhas e vídeos do trabalho realizado pelos detentores de ofícios tradicionais. Em 2010, o MASA conseguiu importantes avanços na região, servindo de referência para o Brasil. Um exemplo foram as leis municipais de reconhecimento dos ofícios tradicionais de saúde popular aprovadas nos municípios de São João do Triunfo e Rebouças.

O processo de promoção dos conhecimentos associados a plantas medicinais vem sendo discutido no Paraná, principalmente por movimentos sociais, universidades, ONGs e pastorais sociais. Várias são as ações efetuadas no sentido de buscar valorizar e aprimorar o uso de plantas medicinais, principalmente nas diversas formas de preparados, como chás, pomadas, xaropes, tinturas, elixires, comprimidos, etc.

Esse processo visa à promoção das práticas fitoterápicas e das práticas integrativas de saúde, buscando valorizar e fomentar o uso dos produtos da farmacopeia brasileira. Podemos citar o trabalho realizado pela Universidade do Centro-Oeste, campus de Francisco Beltrão, no Paraná, que, juntamente com organizações locais, discutiu e aprovou um plano de valorização da cadeia de plantas medicinais e práticas integrativas.

Ainda no Brasil, o debate sobre tratamentos alternativos e práticas integrativas no SUS tem ganhado espaço, principalmente em eventos como o Encontro Holístico Brasileiro - Conferência de Saúde, Ciência e Espiritualidade, em Porto Alegre, evento anual que no ano de 2017 realizou a sua $11^{\circ}$ edição. Esse evento promove encontros paralelos, com discussões e troca de experiências sobre diversas práticas, como Seminário Nacional da Arteterapia, Seminário Nacional da Ayurveda, Seminário de Benzedeiras e Seminário Nacional de Implantação das Práticas Integrativas nos Municípios.

O Brasil dispõe de diversas leis e tratados internacionais que buscam valorizar a diversidade biológica e as formas tradicionais com que os povos e as comunidades tradicionais fazem uso dos recursos naturais. $\mathrm{O}$ Decreto no. 6.040, de 7 de fevereiro de 2007, institui a Política Nacional de Desenvolvimento Sustentável dos Povos e Comunidades Tradicionais, que tem como objetivo específico: "Apoiar e garantir a inclusão produtiva com a promoção de tecnologias sustentáveis, respeitando o sistema de organização social dos povos e comunidades tradicionais, valorizando os recursos naturais locais, práticas, saberes e tecnologias tradicionais". 
A Política Nacional de Plantas Medicinais e Fitoterápicos, criada pelo governo federal no ano de 2006, tem como objetivo expandir e valorizar a diversidade de plantas medicinais utilizadas, bem como proteger e promover os conhecimentos tradicionais, repassando-os de geração em geração. A Política Nacional das Plantas Medicinais e Fitoterápicos, em uma de suas diretrizes, tem como propósito "promover e reconhecer as práticas populares de uso de plantas medicinais e remédios caseiros". Diversas legislações internacionais, das quais o Brasil é signatário, protegem também esses conhecimentos e práticas tradicionais, com destaque para a Convenção 169, da UNESCO, sobre a proteção e a promoção da diversidade das expressões culturais, que classifica esses conhecimentos e as práticas tradicionais culturais como patrimônio imaterial cultural. Para alcançar esses objetivos, os países signatários devem adotar todas as medidas necessárias para a sua proteção.

A manutenção das práticas dos ofícios tradicionais relacionados aos saberes tradicionais sobre o uso dos recursos naturais, principalmente plantas medicinais, faz com que essa experiência apresentada torne-se referência para o desenvolvimento desses grupos tradicionais.

\section{Metodologia}

O mapeamento social é uma metodologia por meio da qual os grupos, através dos mapas, materializam suas práticas e conhecimentos tradicionais, bem como se autoidentificam. Através da autorrepresentação da realidade em "croquis", mapas redigidos pelo próprio grupo, coloca-se neste mapa tudo que é significativo para o grupo, bem como a materialização de todos os conflitos socioambientais e práticas culturais tradicionais. De acordo com Herlihy \& Knapp (2003) (apud ACSELRAD; COLI, 2008, p.15), ”o mapeamento participativo é aquele que reconhece o conhecimento espacial e ambiental de populações locais e insere em modelos mais convencionais de conhecimento". Essa prática de mapeamentos sociais participativos expandese mundialmente após a década de 1990. Nesse processo, os agentes locais são capacitados para ir até os detentores de ofícios tradicionais e coletarem dados sobre suas práticas e conhecimentos tradicionais que fazem parte do patrimônio imaterial cultural. Após a demanda dos movimentos e organizações, solicitam-se a pesquisadores que realizem oficinas de uso de equipamentos como: gravadores, GPS e máquina fotográfica, que serão utilizados na pesquisa pelos próprios agentes das organizações. Em uma segunda etapa, em uma oficina de mapas nas próprias comunidades, os grupos constroem seus croquis, baseados nas práticas e conflitos encontrados. Nesse momento, os agentes de pesquisa que são dos movimentos sociais e 
entidades parceiras materializam esses dados e conflitos, sendo estes em muitos casos alvo de discussão e discordância entre os participantes. Somente após um consenso, as informações são desenhadas em "croquis" (mapas), que depois são repassados para uma base cartográfica, transformando os dados em um mapa da realidade social.

Essa atividade tem cunho formativo. Logo depois de identificadas as pessoas detentoras de ofícios tradicionais, as lideranças do MASA mobilizavam as benzedeiras para espaços de troca de experiências sobre o uso das plantas medicinais e práticas tradicionais de cura como: benzimentos, simpatias, orações, puxados, costura de rendidura, garrafadas e remédios caseiros, etc.

Nessas reuniões denominadas pelo MASA de encontros comunitários, as benzedeiras e praticantes de demais ofícios tradicionais expunham suas experiências para outros portadores, buscando a troca de experiências e a identificação de seus antagonistas. Também discutiam ações para resgatar e promover os ofícios tradicionais e a cultura religiosa local, assim como planejar estratégias para enfrentar os conflitos apontados pelo grupo. Essas oficinas são ações formativas que buscam formar lideranças para trabalhar na promoção e na valorização dos ofícios tradicionais e da cultura local. Esses portadores de ofícios tradicionais se somarão às organizações que os representam, nas quais, posteriormente, ajudarão a compor o quadro de lideranças do MASA.

A metodologia do mapeamento social com as oficinas de autocartografia busca identificar e mapear tudo que é significativo culturalmente para o grupo. De acordo com Almeida (2008, p.17), "a auto cartografia é um instrumento pelo qual o grupo apresenta a sua concepção de território a sociedade". Essa metodologia participativa proporciona que os próprios sujeitos, nesse campo de estudo as benzedeiras, sejam capacitados e desenhem o seu mapa de acordo com suas noções e sua representação do espaço e de suas práticas. Essa metodologia buscou, através de entrevistas, identificar quais ofícios são praticados e como as pessoas se autoidentificam. Lembrando que muitas benzedeiras, em um primeiro momento, não declaravam exercer tal ofício, devido ao processo de repressão desencadeado por entidades religiosas e a medicina oficial. Uma das benzedeiras entrevistadas, Helena de Jesus Rodrigues, quando indagada sobre o que é ser benzedeira, respondeu o seguinte: “É uma profissão, um dom que a pessoa tem, que o Espírito Santo coloca na gente, vou lá no fulano que cura, não é eu que curo, eu peço para Deus abençoa o remédio, a oração que a gente faz, que Deus faça o possível de melhorar, eu graças a Deus fui 
sempre atendida". Referindo-se aos conflitos que enfrentou, Dona"Heleninha", como é conhecida na comunidade, ressalta o seguinte:

Até que agora não está tanto, dizer fulano é feiticeiro, diminuiu um pouco a procura de cura, pois os carismáticos, fazem e é bom, os crentes fazem e é bom, é tudo bom para a gente, sempre tem um que diz é Jesus que cura, é claro que é Jesus, mais a gente tem o dom de pedir, cada simpatia, cada benzimentos é um santo, pra queimadura é um, pra ofensa de cobra é outro, pra costura é outro, mas Jesus está junto toda vida, a gente tem os advogados da gente, para curá criança de susto é são Benedito e Santo Antônio, porque eles cuidaram do menino Jesus depois que nossa senhora apartou (Helena de Jesus Rodrigues, benzedeira e costureira de machucadura, Faxinal dos Seixas, novembro, 2007).

Nesse encontro, foi eleita uma coordenação do Movimento Aprendizes da Sabedoria (MASA), que, juntamente com a assessoria do Instituto Equipe de Educadores Populares, responsabilizou-se por articular uma pesquisa. Como na região já tinha o Projeto Nova Cartografia Social dos Povos e Comunidades Tradicionais, o MASA entrou em contato com os pesquisadores, que levaram a demanda até o Projeto Nova Cartografia Social.

Durante a pesquisa, foram realizadas muitas oficinas de produção de mapas, nas quais, através da metodologia do projeto de autocartografia social, as benzedeiras, benzedores e costureiros representavam suas práticas e seus conflitos em croquis, fazendo um mapa da realidade de cada comunidade pesquisada.

Dentre as principais discussões que emergiram nas oficinas e nos encontros comunitários, algumas coisas foram sendo reveladas, como o uso do termo pejorativo "bocoieiro", para identificar as pessoas que atuavam com práticas tradicionais de cura, como benzimentos, simpatias, orações, defumações, remédios caseiros e homeopatia. Esse termo surgiu na década de 1950, derivado de "bocó", denominação popular dada às sacolas que as pessoas das comunidades que detinham um vasto conhecimento sobre essas práticas, sobretudo de homeopatia, usavam para carregar vidros e remédios.

\section{RESULTADOS}

A pesquisa realizada por meio dos mapeamentos sociais dos ofícios tradicionais de cura religiosa e saúde popular resultou em mapas produzidos pelos próprios grupos, que depois foram passados para cartas topográficas dos respectivos municípios. No ano de 2012, resultou na publicação do Boletim Informativo no 1, do Projeto Nova Cartografia Social dos Povos e 
Comunidades Tradicionais do Brasil, com o título:"Conhecimentos tradicionais e mobilizações políticas: o direito de afirmação da identidade de benzedeiras e benzedores, municípios de Rebouças e São João do Triunfo, Paraná". Foi o primeiro que retrata a discussão de políticas públicas e do mapeamento dos ofícios tradicionais associados à saúde popular no Brasil.

Os mapeamentos sociais possibilitaram ainda a ampliação do debate sobre os conhecimentos e as práticas tradicionais de cura utilizados, bem como os conflitos enfrentados por esses grupos. O mapeamento mostrou a realidade dos grupos, com a localização e a identificação dos diversos ofícios tradicionais presentes, inicialmente no município de Rebouças (2009), que mapeou 133 ofícios, e depois em São João do Triunfo (2011), com 163 detentores, e Irati (2017), com 187 ofícios tradicionais de cura religiosa e saúde popular.

Através dos mapeamentos sociais realizados em três cidades até o momento, o Movimento Aprendizes da Sabedoria dos ofícios tradicionais de cura do Paraná indica a existência de uma população de aproximadamente 17.000 pessoas no estado, praticantes da arte de curar e ensinar remédios caseiros, colaborando diretamente para a saúde de milhares de pessoas e para a saúde pública em todos os municípios paranaenses.

Os principais conflitos referidos a esses grupos se encontram na repressão dos conhecimentos e práticas tradicionais de cura, praticada por diversas pessoas ligadas a instituições religiosas e à medicina oficial. Outra situação enfrentada por esses grupos se traduz na disputa pelo acesso aos recursos florestais medicinais, com a privatização do seu uso, além de diversas formas de preconceito e críticas de que são vítimas, praticadas por diversas pessoas da sociedade.

Durante o mapeamento, vários encontros e reuniões de articulação política foram realizados pelo MASA com secretários de saúde, vereadores e prefeitos dos municípios. Fruto dessas demandas apresentadas e da pressão exercida, tem-se a conquista de duas leis municipais.

[...] com fundamento nos dados dos mapeamentos sociais, foi a aprovação de legislações especificas de reconhecimento dos Benzedores. Desta maneira, com muita dedicação das lideranças do MASA na negociação política com as Câmaras Municipais de vereadores, Prefeituras municipais e demais secretarias, em 03/02/2010 foi aprovada a primeira "Lei das Benzedeiras", isto é, a Lei Municipal n 1401 de Rebouças. E em 22/02/2012 foi promulgada a segunda "Lei das Benzedeiras", ou seja, a Lei Municipal n¹370 pelo presidente da Câmara Municipal de São João do Triunfo [...] (MASA, 2012, pg.12). 
Ambas as leis municipais reconhecem os ofícios tradicionais e suas práticas de cura, com direito a certificado de reconhecimento, carteirinha e livre acesso às plantas medicinais nativas nos municípios. A Lei Municipal no 1370, de 2011, do município de São João do Triunfo, no Paraná, traz o seguinte artigo, que trata do processo de reconhecimento e solicitação da carteirinha de benzedeira.

Art.10- A consciência de sua identidade de Detentor de Ofício Tradicional de Cura, associado a saberes, conhecimentos e práticas tradicionais de cura é o critério fundamental para o seu reconhecimento pelo Poder Público Municipal.

$\S 1^{\circ}$ - Para Fins desta Lei, as pessoas que desejarem obter o Certificado de Reconhecimento de Detentor de Ofício Tradicional de Cura e a Carteira de Reconhecimento de Detentor de Ofício Tradicional de Cura em suas diferentes modalidades, deverão solicitar a Secretária Municipal de Saúde, mediante sua auto definição, que poderá ser seguido de reconhecimento da coletividade usuária de seus serviços de proteção à saúde, se o solicitante desejar.

Já em Rebouças, a Lei Municipal no 1401, de 2010, dá os mesmos direitos às benzedeiras e as reconhece como sendo importantes para a saúde pública do município, em seu Artigo 30:"O Município de Rebouças reconhece os saberes e os conhecimentos localizados realizados por detentores de 'Ofícios Tradicionais' como instrumentos importantes para a saúde pública do município".

Ainda referente ao problema das benzedeiras de não poderem ter acesso a determinadas plantas medicinais em reservas particulares e áreas fechadas, a Lei Municipal no 1401, de 2010, de Rebouças, Paraná, estabelece o seguinte:

Art.4 - As plantas nativas de uso medicinal existentes no município de Rebouças são de livre acesso e uso comum das pessoas, que desejam realizar tratamentos medicinais, desde que orientados por Detentores de "ofícios tradicionais" reconhecidos pelo Poder Público Municipal, sempre observando o uso sustentável e a conservação ambiental.

As leis formam importante instrumento jurídico para a formalização dos ofícios, pois, além de garantir os direitos de benzer sem repressão, representam uma ferramenta essencial para a valorização da identidade de benzedeira, benzedor, costureira de rendidura, remedieiro e parteira. 


\section{CONSIDERAÇÕES FINAIS}

Essa experiência revela que mapeamentos sociais participativos podem ser uma ferramenta importante para a formação de grupos sociais organizados em identidades coletivas, permitindo que eles, juntamente com suas entidades, lutem pela implementação de políticas públicas de reconhecimento e valorização dos conhecimentos tradicionais presentes nos ofícios tradicionais de cura religiosa e saúde popular.

A experiência relatada mostra que a pesquisa pode contribuir com esses grupos sociais organizados em movimento social, no sentido de gerar dados para retirar da invisibilidade social esses sujeitos, possibilitando a inserção desses grupos em políticas públicas. Os encontros realizados entre os detentores de ofícios tradicionais na região foram o princípio de uma formação com o objetivo de aprimorar a demanda de políticas de reconhecimento e manutenção de suas práticas e saberes associados a plantas medicinais e remédios caseiros, bem como o início de uma luta para o reconhecimento formal dos ofícios tradicionais de benzedeira, benzedor, curador, costureira (o) de rendidura, remedieiro e parteira.

Nesse tempo de luta do MASA, grandes conquistas ocorreram, como dois prêmios nacionais. A primeira premiação foi o Prêmio Cultura e Saúde (2010), do Ministério da Cultura, e a segunda foi conquistada em 2011, através do Instituto do Patrimônio Histórico e Artístico Nacional (IPHAN), na categoria de Bens de Natureza Imaterial, com a realização dos mapeamentos sociais em Rebouças e São João do Triunfo. Em 2015, houve mais uma premiação do edital Cultura em Rede do Ministério da Cultura. O MASA foi contemplado tendo em vista a ação articulada do movimento social com entidades da região sobre o trabalho de resgate e valorização das benzedeiras e da cultura religiosa tradicional local.

SOCIAL MAPPING AS A TOOL FOR DISCUSSION OF PUBLIC POLICIES FOR THE FORMAL RECOGNITION OF BENZEDEIRAS IN PARANÁ

ABSTRACT:This work presents analyses about the Social Mapping process of Benzedeiras, Benzedores, Curators, Dressmakers of Machucadura, Remedieiros, Traditional Masseurs and Midwives performed in the municipalities of Rebouças and São João do Triunfo in Paraná. This work carried out by the Apprentice Movement of Wisdom with the 
support of researchers of the new social cartography project represented an important tool to identify the diversity of subjects who identify themselves as having traditional religious healing and popular health services. It can be seen that social mapping was an instrument to generate discussion about traditional practices and conflicts faced by groups, as well as giving visibility to public authorities for the construction of public recognition policies.

KEYWORDS: Social mapping. Traditional crafts. Conflicts. Public policy.

\section{MAPEAMENTOS SOCIALES COMO HERRAMIENTA PARA DISCUSIÓN DE POLÍTICAS PÚBLICAS PARA EL RECONOCIMIENTO FORMAL DE BENZEDERAS EN PARANÁ}

RESUMEN: En este trabajo se presenta un análisis del proceso de Asignaciones Sociales charlatanes, curanderos, curadores, Costureras hematoma, Remédieiros, masajista y parteras tradicionales llevaron a cabo en los municipios de Rebouças y São João do Triunfo, en Paraná. Este trabajo realizado por los aprendices Movimiento de la sabiduría con el apoyo de investigadores del nuevo proyecto de mapeo social representa una herramienta importante para identificar la diversidad de temas que se auto identifican como personas que tienen oficios tradicionales de curación religiosa y popular de salud. Se observa que el mapeo social es una herramienta para generar la discusión sobre las prácticas tradicionales y los conflictos que enfrentan los grupos y dar visibilidad al gobierno para construir políticas de reconocimiento público.

Palabras Clave: Cartografía Social. La artesanía tradicional. Conflictos. Política pública.

\section{REFERÊNCIAS}

ACSELRAD, H. (Org.). Cartografias sociais e território. Rio de Janeiro: Universidade Federal do Rio de Janeiro; Instituto de Pesquisas e Planejamento Urbano e Regional, 2008.

ALMEIDA, A. W. B. (Org.). Série de fascículos com o uso do mapeamento participativo junto a populações tradicionais. Projeto Nova Cartografia Social da Amazônia. Manaus: PPGSCA-UFAM, FAPEAM-CNPq, 2008. 18p.

ASSOCIAÇÃO APRENDIZES DA SABEDORIA. Faxinalenses: fé, conhecimentos tradicionais e práticas de cura. Projeto Nova Cartografia Social do Brasil. Irati: UFAM, 2008.

BOLETIM INFORMATIVO Nova Cartografia Social dos Povos e Comunidades Tradicionais. Conhecimentos Tradicionais e Mobilizações Políticas: O direito de afirmação da identidade de benzederias e benzedores, municípios de Rebouças e São João do Triunfo. Volume 1. Edição Especial, 2012. 16 páginas. 
BRASIL. Comissão Nacional de Desenvolvimento Sustentável dos povos e comunidades tradicionais. Política Nacional de Desenvolvimento Sustentável dos povos e comunidades tradicionais. Folder divulgação. MDS. 2007.

COMISSÃO NACIONAL DE DESENVOLVIMENTO SUSTENTÁVEL DOS POVOS E COMUNIDADES TRADICIONAIS. Política Nacional de Desenvolvimento Sustentável dos Povos e Comunidades Tradicionais. Folder divulgação. MDS. 2007.

HERLIHI, P. H.; KNAPP, G. (Ed.). 2003. Maps of, by and for the peoples of Latin America. Human Organization. Journal of the Society for Applied Anthropology. v. 62, n. 4, Winter 2003.

MOVIMENTO APRENDIZES DA SABEDORIA. Boletim Informativo Nova Cartografia Social. Conhecimentos tradicionais e mobilizações políticas. Manaus: Editora da Universidade do Estado do Amazonas, 2012.

$1^{\circ}$ Encontro Regional das Benzedeiras, Rezadeiras, Curadores, Costureiras e Parteiras, Conhecimentos Tradicionais e Saberes Populares, Conservando a Biodiversidade e Cuidando da Vida. Cartilha. Irati. 2008.

Conhecimentos tradicionais e práticas de saúde popular: sabedoria popular cuidando da vida. Cartilha. Irati, 2009.

PIMENTA, T. S. Terapeutas populares e instituições médicas na primeira metade do século XIX. In: CHALOUB, S. et al.(Org.). Artes e ofícios de curar no Brasil 308-330. Campinas, SP: Editora da UNICAMP, 2003.

REBOUÇAS (Município). Lei Municipal 1401, 11 de fevereiro de 2010. Dispõe sobre o processo de reconhecimento dos ofícios tradicionais de saúde popular em suas distintas modalidades: benzedeiros (a), curadores, costureiros (a) de rendiduras ou machucaduras e regulamenta o livre acesso à coleta de plantas medicinais nativas no município de Rebouças, Estado do Paraná, conforme especifica. Rebouças, PR, 11 fev. 2010.

Antonio Michel Kuller Meira: Possui Graduação em Licenciatura Plena em Geografia, mestrando em Educação pela Universidade Estadual do Centro-Oeste (UNICENTRO/PR). Tem experiência na área de Educação Não Formal e Educação no Campo, com ênfase em Conhecimentos e Comunidades Tradicionais. Especialização em Educação do Campo pela Universidade Federal do Paraná - Setor litoral. Atuando principalmente nas seguintes áreas: Agroecologia, Povos e Comunidades Tradicionais, Agroflorestas, Educação Não Formal, Educação no Campo, Organização Popular, Conhecimentos e Ofícios Tradicionais de Saúde Popular.

E-mail:amkmeira@yahoo.com.br 